Estudos Linguísticos

Linguistic Studies 



\title{
A CONSTRUÇÃO DA AUTORIA NA REESCRITA DE TEXTOS: EFEITOS DA INTERAÇÃO PROFESSOR-ALUNO
}

\author{
The construction of authorship in the rewriting of \\ texts: effects of interaction between teacher and \\ student
}

\author{
Evandro Gonçalves Leite* \\ Regina Celi Mendes Pereira**
}

\begin{abstract}
RESUMO
Neste trabalho, investigamos a prática de reescrita textual de alunos advinda da mediação do professor, no sentido de perceber as influências dessa mediação no trabalho dos alunos e os efeitos dela para a formação desses sujeitos como autores de seus textos. Para tanto, observamos, durante uma proposta de produção textual, duas situações de reescrita encaminhadas (uma coletiva e outra individual), a fim de analisar comparativamente os efeitos que a reescrita coletiva, efetuada conjuntamente pelo professor e pela turma a partir do texto de um aluno da classe, exerce sobre dois textos escritos dos alunos - cada um em sua primeira versão, com a correção do professor, e na versão reescrita. Nosso estudo baseia-se em reflexões sobre o ensino da produção escrita e da reescrita textual e sobre o conceito de autoria; bem como nos estudos do Interacionismo Sociodiscursivo, quanto às capacidades e operações de linguagem constitutivas dos textos, para reconhecer as semelhanças e/ou diferenças entre a reescrita coletiva e a individual. As análises permitem-nos afirmar que a reescrita coletiva conduzida pelo professor exerce forte influência sobre a reescrita individual dos alunos, os quais (praticamente) abandonam seu projeto de
\end{abstract}

* Professor de Língua Portuguesa e Literatura do Instituto Federal de Educação, Ciência e Tecnologia do Rio Grande do Norte. Mestre em Linguística pela Universidade Federal da Paraíba (2009).

** Professora Adjunta IV (DLCV/PROLING/UFPB) e bolsista de produtividade em pesquisa 2 do CNPq. Doutora em Letras pela Universidade Federal de Pernambuco (2005). 
dizer da primeira versão e a correção escrita em seus textos, (re) elaborando-os em função do texto legitimado pelo professor na reescrita coletiva. Portanto, a mediação que o professor realiza através da reescrita coletiva não é, nesses casos observados, positiva para a formação dos alunos enquanto produtores de textos, ao abdicarem de seu projeto de dizer e, consequentemente, de suas condições de autores.

Palavras-chave: correção; reescrita; autoria.

\begin{abstract}
This paper intends to investigate the students' practice of textual rewriting under teacher mediation, in the sense of perceiving the influence of such mediation on students' work and its effects on students' formation as authors of their own texts. To do so, we observed, during a proposal of textual production, two situations of rewriting put forth (one collective and another individual), in order to comparatively analyze the effects that the collective rewriting, carried out by both the teacher and the class together starting from a text written by a student in the classroom, plays on two students' written texts - each one in its first version, with the teacher's correction, and in the rewritten version. Our study is based on reflections about the teaching of writing production and textual rewriting, and on the concept of authorship; as well as on studies of the Socio-discursive interactionism, regarding the capacities and operations of languages which constitute the texts, in order to recognize the likenesses and/or differences between the collective and individual rewriting. The analyses enable us to state that the collective rewriting led by the teacher plays a strong influence on students' individual rewriting, making them (practically) abandon both their text project of the first version and the writing correction in their texts, (re)developing them in function of the text legitimated by the teacher in the collective rewriting. Therefore, the mediation accomplished by the teacher through the collective rewriting is not, in these cases observed, positive for the students' formation as text producers, since they abdicated their text project and, in consequence, their status as authors.
\end{abstract}

Keywords: correction; rewriting; authorship.

\title{
1 INTRODUÇÃo
}

Este trabalho aborda uma das etapas da produção de textos escritos nas aulas de língua materna: a reescrita textual de alunos orientada pela 
mediação do professor como parceiro mais experiente. O objetivo é analisar como os alunos interagem com o professor e suas formas de mediação na prática da reescrita textual e os efeitos dessa interação para construção dos alunos como autores. Sabemos que, numa perspectiva dialógica e polifônica, muitas são as vozes e os sujeitos com os quais os alunos interagem ao produzir seus textos. Nosso trabalho, no entanto, visa a compreender tão somente a influência da mediação do professor nesse processo e os resultados a que ela conduz, especialmente no tocante à autoria.

Para isso, observamos textos dissertativos - a primeira versão e a reescrita - elaborados por alunos e posteriormente submetidos a duas situações de refacção textual: uma coletiva, em conjunto com o professor; e outra individual, realizada somente pelo aluno em seu respectivo texto, mas antecedida da correção escrita do professor. Os textos foram coletados durante observação de aulas de Língua Portuguesa em uma turma de $9^{\circ}$ ano do Ensino Fundamental de uma escola pública. Esses dados serão analisados à luz de estudos sobre a produção textual na escola, notadamente os processos de correção e reescrita, e sobre o conceito de autoria; e à luz do Interacionismo Sociodiscursivo, que fornece as categorias de análise, a saber, as capacidades e operações de linguagem definidas por Bronckart $(1999,2006)$ como constituintes de todo e qualquer texto.

$\mathrm{O}$ artigo encontra-se organizado da seguinte forma: primeiramente, apresentamos algumas reflexões acerca dos conceitos de correção e reescrita e seu imbricamento com as demais etapas do processo de produção textual, assim como sobre a noção de autoria; posteriormente, expomos os procedimentos metodológicos para a coleta dos dados, descrevendo o desenvolvimento das situações de reescrita textual (coletiva e individual), e delineamos as categorias para análise desses dados, fincadas nos estudos do Interacionismo Sociodiscursivo; em seguida, realizamos a análise dos dados, apresentando dois textos de alunos - cada um deles em sua primeira versão, com a correção, e na versão reescrita - e confrontando-os com a reescrita coletiva; por fim, discutimos os resultados, comparamos as análises dos dois textos e fazemos as considerações finais.

\section{CONSIDERAÇõES SOBRE REESCRITA, MEDIAÇÃo E AUTORIA}

A reescrita textual, objeto de estudo do presente trabalho, está inserida num processo mais amplo. Desse modo, antes de conceituá-la mais detalhadamente, convém apresentarmos, de modo panorâmico, algumas reflexões acerca do processo da escrita. 
É preciso esclarecer que a escrita é um meio de comunicação/interação entre pessoas e serve para orientar, coordenar ações e, ainda, fazer negócios; ou seja, a escrita pode ser compreendida como meio de interação, aprendizagem e participação social. Na visão de Geraldi (1997), para escrever é fundamental que:
a) se tenha o que dizer;
b) se tenha uma razão para dizer o que se tem a dizer;
c) se tenha para quem dizer o que se tem a dizer;
d) o locutor se constitua para tal, enquanto sujeito que diz o que diz para quem diz;
e) se escolham as estratégias para realizar (a), (b), (c) e (d) (GE- RALDI, 1997, p. 137).

A produção de textos escritos pressupõe, então, um locutor numa determinada posição social, um objetivo e um destinatário, condições que orientam as demais estratégias e habilidades postas em prática na textualização. Assim, além das questões linguísticas e textuais, por exemplo, a qualidade do texto passa também pela definição de um projeto de dizer do produtor e pela construção deste como sujeito-autor.

Segundo Possenti (2002):

[...] a questão da qualidade do texto passa necessariamente pela questão da subjetividade e de sua inserção num quadro histórico - ou seja, num discurso - que lhe dê sentido. o que se poderia interpretar assim: trata-se tanto de singularidade quanto de tomada de posição (POSSENTI, 2002, p. 115).

Dessa forma, a subjetividade é condição necessária para que haja autoria e, nesse processo, o autor assume duas atitudes: dar voz a outros enunciadores e manter a distância em relação ao próprio texto. A primeira refere-se ao modo como incorporamos, no próprio texto, vozes do outro e as avaliamos; a segunda, à tomada de posição em relação ao que dizemos e em relação ao interlocutor. Não estamos pregando a existência de um autor completamente isolado, individual e todo-poderoso; mas, a despeito de certas restrições impostas pelos gêneros, pela língua e pelas formações sociodiscursivas, o sujeito pode atuar sobre a linguagem, "[...] por intervir e recortar um espaço para si ao enunciar de um modo peculiar, ao tomar posição e por possuir um projeto de texto. [...]" (BAPTISTA, 2005, p. 90)

Assim, o sujeito, ao escrever, deve mobilizar e coordenar, simultaneamente, um conjunto de habilidades diversas - conhecimento do sistema 
de escrita, do conteúdo a ser expresso no texto, da organização textual, da situação enunciativa (locutor, destinatário, objetivos, contexto) e dos tipos de enunciados adequados a ela.

Nesse processo, a reescrita pode constituir um momento significativo de aprendizagem das regras e usos da escrita. A reescrita, na visão de Garcez (1998), é uma oportunidade de o redator explicitar seus conhecimentos e dúvidas, procurar soluções, raciocinar sobre o funcionamento da língua; dessa forma, aprender diversas habilidades envolvidas no domínio da modalidade escrita.

Essa capacidade reflexiva demanda que seja um processo aprendido gradativamente. $\mathrm{O}$ sujeito, quanto mais se relaciona com $o$ texto, considerando o seu caráter dialógico, mais desenvolve as capacidades de planejar, escrever, analisar e reescrever segmentos do texto (D'ELIA, 2007, p. 30).

Portanto, o desenvolvimento de capacidades para a produção de textos implica uma atitude reflexiva perante a linguagem: a reescrita textual, que, partindo das necessidades de aprendizagem (os erros) evidenciadas nos textos, paulatinamente tornaria os alunos autocorretores.

Essa prática de reescrita pode ser individual, em duplas ou em grupos maiores; ser orientada por uma intervenção mais sistemática do professor ou de um material didático, ou até constituir uma tarefa em que o próprio aluno é solicitado a revisar e reelaborar seu texto sem orientações de outro leitor; incidir sobre o texto inteiro ou sobre alguns fragmentos apenas. Esses diferentes encaminhamentos que podem ser suscitados dependem, evidentemente, de um conjunto de variáveis, dentre os quais podemos citar: os objetivos da tarefa, a quantidade de alunos por turma, a formação do professor e as condições do trabalho docente. Neste trabalho, interessa-nos particularmente a reelaboração coletiva e individual de todo o texto, visto serem estas as estratégias utilizadas pelo professor nas propostas de reescrita que compõem o corpus.

Nesse processo de reflexão sobre os erros visando à formação da capacidade de autocorreção, o aluno necessita de assessoramento. Logo, é preciso que haja a indicação de "instrumentos de apoio" (Cf. CABRAL, 1994), a orientar a tarefa proposta; ou seja, critérios que auxiliem a reelaboração textual, principalmente quando se trata de aprendizes. Desse modo, atestamos a importância da participação do outro e da avaliação como elementos indispensáveis à construção/desenvolvimento de habilidades de escrita pelos alunos, que, ao internalizarem os critérios dessas avaliações mediadas por outros parceiros, adquirem a capacidade de atuar criticamente sobre seus 
próprios textos. Esse papel do outro como ponto de apoio é de tal forma decisivo que, durante a refacção, o aluno tende a amparar-se nos questionamentos e comentários daquele sujeito para buscar as soluções adequadas aos problemas do texto (Cf. ALMEIDA, 2001).

Duas das formas de intervenção mais explícitas são a correção escrita que o professor realiza no texto do aluno e a reescrita coletiva encaminhada pelo professor.

Correção pode ser definida como:

[...] o trabalho que o professor (visando à reescritura do texto do aluno) faz nesse mesmo texto, no sentido de chamar a sua atenção para algum problema de produção. Correção é, pois, o texto que o professor faz por escrito no (e de modo sobreposto ao) texto do aluno, para falar desse mesmo texto (RUIZ, 2001, p. 27, grifo da autora).

A correção também é vista sob uma perspectiva processual, pois não corresponde ao ponto final da produção do texto: é um elo na cadeia dessa interação. A correção está, então, inserida e articulada num processo mais amplo.

Já a reescrita coletiva é uma estratégia de reelaboração textual monitorada pelo professor. Ela consiste na refacção de aspectos problemáticos de um texto ou de fragmento(s) de texto(s), a depender dos objetivos e critérios eleitos para a tarefa. Nesse sentido, os alunos são convocados, coletivamente, a refletir sobre as possibilidades de reestruturação (exclusão, acréscimo, substituição, deslocamento), e o professor atua como o articulador da atividade, coordenando as intervenções dos alunos, indagando e negociando as melhores alternativas para o texto objeto de análise.

Como vemos, a reescrita pode constituir ferramenta de construção de conhecimentos pelos alunos acerca da escrita. A natureza da intervenção do professor nesse processo, por sua vez, será preponderante para o desenvolvimento e os resultados da atividade. Numa perspectiva interacionista, a mediação de outros sujeitos é condição fundamental para a construção de conhecimentos. Os interacionistas sociais compartilham a tese de que as condutas humanas são decorrentes de um longo processo de socialização; eles defendem que, embora algumas propriedades comportamentais humanas possam ser determinadas geneticamente, outras só podem ser construídas historicamente pela interação social. Nas palavras de Dolz e Schneuwly (2004, p. 46): “[...] Para o 'interacionismo social', a consciência de si e a construção das funções superiores são estreitamente dependentes 
da história de relações do indivíduo com sua sociedade e da utilização da linguagem. [...]".

Em síntese, vemos que o outro é condição essencial para a aquisição da linguagem e, por conseguinte, o desenvolvimento de habilidades de escrita pelos alunos, dentre elas a construção destes como autores. As atividades de reescrita podem ser entendidas nessa perspectiva, como modos de inserção do outro (neste caso o professor) nesse processo de aprendizagem.

Mais à frente, faremos uma análise acerca da influência do professor no processo de (re)escrita textual dos alunos, bem como avaliaremos os resultados a que o tipo de interação proposto conduz.

\section{Metodologia}

Antes de procedermos à análise propriamente dita, é necessário situarmos o contexto em que a prática de (re)escrita se deu. Realizamos observações $^{1}$ de aulas de Língua Portuguesa em uma turma de $9^{\circ}$ ano do Ensino Fundamental de uma escola pública da rede municipal de ensino de São Miguel - RN. Algumas dessas aulas foram dedicadas à produção de uma dissertação escolar com o seguinte tema: "O Brasil é um país preconceituoso ou não?". Antes de encaminhar a produção do texto, o professor realizou, em aulas anteriores, atividades diversas sobre o tema e expôs, de forma superficial, o conceito e a estrutura do gênero, exemplificando com a posterior leitura de um exemplar dele.

A dissertação é inspirada, segundo Baltar (2004), na tipologia aristotélica de classificação dos textos. Entretanto, essa tipologia assumiu historicamente uma condição tão peculiar no ensino da escrita na escola que passou a funcionar como objeto de ensino. Conforme Souza (2003), a escola desenvolve gêneros textuais que fazem parte do próprio funcionamento da instituição. A dissertação é um deles: "[...] um gênero textual pertencente ao domínio discursivo escolar, com o objetivo de desenvolver a competência comunicativa do indivíduo" (SOUZA, 2003, p. 163). Trata-se de um gênero secundário, que pretende capacitar os alunos para discorrerem de maneira lógica sobre um tema, expondo seu ponto de vista sobre ele e empregando os conhecimentos gramaticais. É, pois, um gênero criado para o ensino da produção escrita argumentativa, já que só existe na escola e em exames de redação. Fora desses ambientes, não há outra atividade social que use esse gênero.

${ }^{1}$ Tais observações ocorreram em 2008 , em virtude do desenvolvimento de pesquisa de Mestrado intitulada "A reescritura do aluno sob a orientação do professor". 
Depois de encaminhar a produção da dissertação e recolher os textos dos alunos para corrigi-los, foram desenvolvidas duas práticas de reescrita - uma coletiva e outra individual -, ambas antecedidas de orientações do professor.

A reescrita coletiva consistiu na reelaboração total do texto de um aluno da turma. o professor distribuiu a cada aluno um exemplar do texto, apresentado a seguir: ${ }^{2}$

\begin{tabular}{|l|}
\hline \multicolumn{1}{c|}{ Brasil x Preconceito } \\
tuoso. \\
O Brasil Preconceituoso, mas é claro, que não tem Preconcei- \\
Sim! o Preconceito é no mundo inteiro; mais existe muitos \\
tipos de preconceito lá vai alguns: Preconceito contra Gordinhos; contra \\
loiras, negros. \\
• Gordinho: \\
Iso não é gordura e execo de fofura. \\
• Para as loiras \\
Eu sou loira e você que é encardida. \\
Preconceito; há; o Preconceito; tantas vezes és estudado mas \\
Preconceito nunca! ou preconceito sempre? \\
Devemos enteder o verdadeiro sentido Preconceito não só ser \\
Termino o meu texto foi muito simples mais Pode mudar uma \\
estudado \\
Pessoa.
\end{tabular}

Em seguida, todos, professor e alunos, realizaram uma discussão oral sobre o texto e logo procederam à refacção na lousa. A atividade durou duas aulas de cinquenta minutos cada e contou com a participação dos alunos, a despeito de algumas situações de indisciplina. O texto resultante segue transcrito abaixo e, embora reconheçamos que muitas modificações deveriam ser feitas, principalmente quanto à organização de uma dissertação escolar, as ideias, posicionamentos e argumentos da primeira versão do texto (o projeto de dizer do aluno) não foram considerados. A versão reescrita, desse modo, em nada lembra a primeira e parece mais uma produção coletiva de um outro texto. Vejamos:

${ }^{2}$ A transcrição desse e de todos os demais textos aqui apresentados é completamente 


\section{O brasileiro é preconceituoso}

o povo brasileiro é discriminado por ele mesmo, pois a sua diversificação é grande, existe a desigualdade social além da intolerância das pessoas para conviver com as diferenças.

A diversificação se apresenta de várias formas: massa corporal, cor dos cabelos, da pele, altura, opção religiosa, modo de se vestir, escolha política, gênero musical, entre outros. Por não aceitarmos as diferenças citadas acima, tornamos o Brasil um país preconceituoso.

A desigualdade social é outro grande motivo de preconceito, pois as pessoas com mais condições se acham superiores às que têm menos condições, por exemplo: ao ver um mendigo menospreza-o por está naquela situação.

A intolerância das pessoas também é alvo de preconceito, pois muitas pessoas não aceitam ser diferentes, nem mesmo que os outros sejam. Por exemplo: o negro não se aceita como negro, pobres que não suportam serem pobres.

Diante dos fatores mensionados, podemos afirmar que, realmente, o povo brasileiro é preconceituoso, pois não aceita conviver com as diferenças, o que é prejudicial para o ser humano.

Consideramos que a reescrita coletiva, embora fruto de uma construção da turma, representa, no contexto de sala de aula, um texto validado pelo professor e até emanado dele. Este, no momento da atividade, posiciona-se como o coordenador da tarefa, ao articular as intervenções dos alunos, avalizar as mais adequadas, controlar a inserção delas na construção do texto e inclusive redigi-lo. Reflete, pois, um projeto de dizer autorizado e reconhecido pela turma como legítimo.

Ao término da reescrita coletiva, o professor devolveu, corrigido, cada texto a seu produtor, para que fosse efetuada a refacção individual. A atividade foi encaminhada como tarefa de casa e, na aula seguinte, dez alunos entregaram ao professor os textos reescritos acompanhados da primeira versão.

Desses dez textos, cinco apresentam estreita relação com a primeira versão e com a correção escrita do professor. Cinco, porém, apresentam um comportamento especial: parecem ignorar a correção do professor na primeira versão e o próprio texto anteriormente produzido e relacionarem-se mais com a reescrita coletiva. Esse comportamento especial é que investigaremos neste trabalho, buscando relacionar a reescrita individual dos alunos com o texto coletivo, no intuito de analisar o diálogo que se estabelece entre ambos.

A comparação da reescrita coletiva com a individual será estabelecida mediante propriedades constitutivas dos textos, a saber, as operações 
e capacidades de linguagem descritas por Bronckart $(1999,2006)$. O autor considera os textos como manifestações empíricas de ações de linguagem e, para realizá-las, os sujeitos devem mobilizar um conjunto de conhecimentos, tratados como capacidades de linguagem. Cada capacidade, por sua vez, desdobra-se ainda em operações. Vejamos:

- Capacidades de ação: possibilitam ao sujeito adaptar sua produção à situação de ação de linguagem (representações do conteúdo temático e dos contextos físico, social e subjetivo) e ao gênero textual;

- Capacidades discursivas: possibilitam escolher a infraestrutura textual (tipos de discurso, articulação entre os tipos de discurso, sequências e outras formas de planificação, plano geral);

- Capacidades linguístico-discursivas: possibilitam realizar operações de linguagem implicadas na produção do texto e são de quatro tipos: (1) operações de textualização (conexão, coesão nominal e coesão verbal); (2) mecanismos enunciativos (gerenciamento de vozes e modalizações);

(3) construção de enunciados, orações e períodos; e (4) escolha de itens lexicais.

A análise baseia-se numa amostragem de dois textos representativos dos demais, segue uma abordagem puramente qualitativa e fundamenta-se na observação da versão reescrita dos alunos, comparando-a com a primeira versão e com a reescrita coletiva. Esta não será transcrita na análise, haja vista que já consta neste tópico, mas será mencionada a todo momento.

\section{AnÁlise dos teXtos}

O intuito dessa seção é analisar a influência da mediação do professor, através da reescrita coletiva, na reescrita individual dos dois textos selecionados, considerando cada uma das operações/capacidades de linguagem. Eis o primeiro texto, em sua primeira versão e na versão reescrita: 
TEXTO 1: PRIMEIRA VERSÃO 3

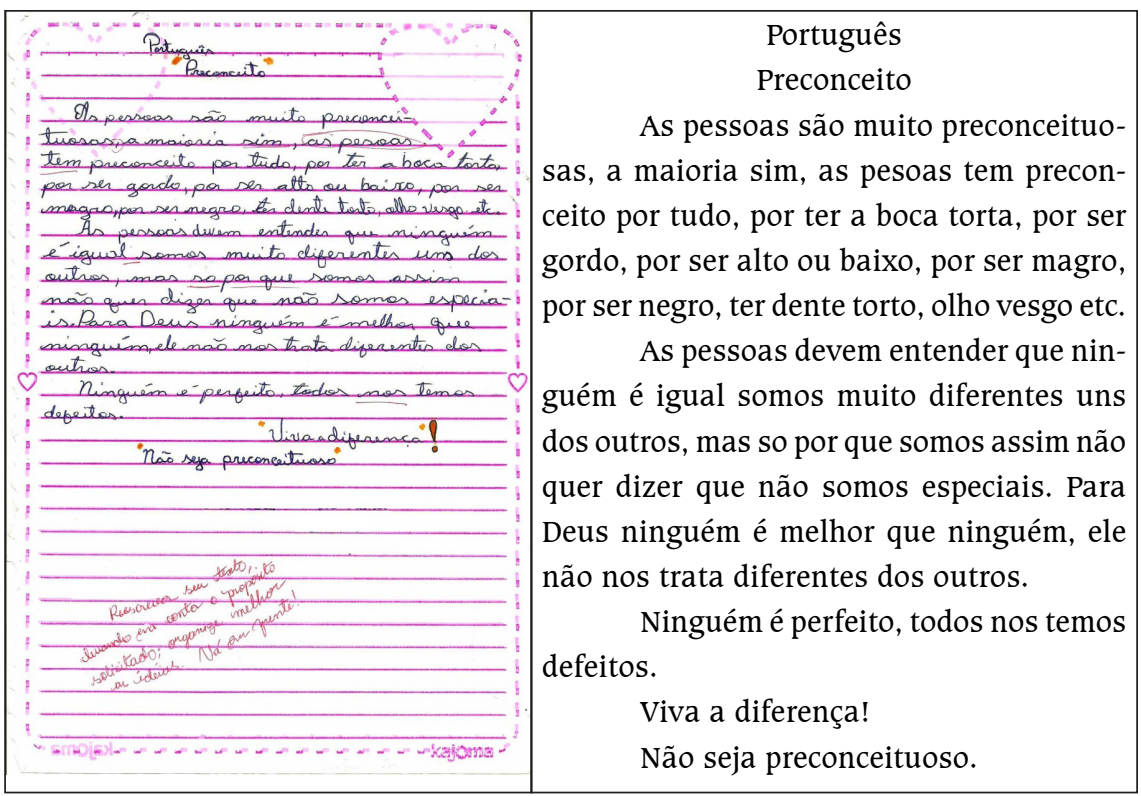

\section{TEXTO 1: VERSÃO REESCRITA ${ }^{4}$}

Os brasileiros são preconceituosos

Os brasileiros são preconceituosos, a maioria dos brasileiros tem preconceito até por ele mesmo, os brasileiros tem preconceito pela desigualdade social e as dificuldades de viver com as pessoas e as suas diferenças.

As pessoas devem entender que ninguém é igual, somos muito diferentes uns dos outros, já pensou se todos fosemos iguais. seria uma chatice. ceituoso.

Por não aceitar as nossas diferenças, tarmos o Brasil precon-

As pessoas com muito dinheiro se acham melhores as que tem menos, as que tem menos naon suportam ter menos.

Então, podemos afirmar que os brasileiros, são preconceituosos, por não aceita conviver com as diferenças, o que acabas prejudicando os brasileiros.

${ }^{3}$ A primeira versão dos textos constará para que fique ainda mais evidente que a reescrita leva em consideração o texto coletivo e quase nunca a primeira versão do próprio aluno.

${ }^{4}$ Não apresentaremos, escaneados, os textos reescritos dos alunos, pelo fato de não implicarem em perda de informações, já que as transcrições são fiéis aos originais. A primeira versão, no entanto, não pôde ser omitida, visto que os leitores perderiam as informações contidas na correção escrita do professor. 
Uma comparação superficial entre a primeira e a segunda versão já nos permite afirmar que o aluno abandona quase completamente seu projeto de dizer inicial. Mas isso acontece não em decorrência das correções do professor - as quais se concentram em problemas bem localizados do corpo do texto (pontuação, acentuação, ortografia, repetição de palavras) ou fazem observações de caráter bastante genérico no pós-texto ("Reescreva seu texto, levando em conta o propósito solicitado; organize melhor as ideias. Vá em frente!") - e sim por influência da reescrita coletiva. Nenhuma das modificações descritas a seguir baseia-se na intervenção escrita do professor na primeira versão.

Em relação às capacidades de ação, o conteúdo temático é reformulado de acordo com o texto coletivo, do qual se torna uma paráfrase. Embora o mesmo tema (o preconceito) continue a ser tratado, outros aspectos são levantados acerca dele: agora, passa-se a focalizá-lo do ponto de vista do Brasil e dos brasileiros, enquanto antes o abordava em sentido mais amplo. Apenas no segundo parágrafo é inserido um assunto relacionado à primeira versão do texto: a afirmação de que as diferenças existem e são benéficas. Retiram-se também as duas frases imperativas que encerram o texto, que não são compatíveis com o gênero dissertação.

A infraestrutura textual também se assemelha bastante à do texto coletivo. Os argumentos são praticamente os mesmos (à exceção de um que é conservado da primeira versão, sobre as diferenças), estão dispostos de modo muito semelhante e também em cinco parágrafos. Observamos que, desde a introdução até a conclusão, ideias e até frases inteiras são repetidas, alterando-se somente algumas palavras ou alguns aspectos linguísticos como a concordância, por exemplo. Na reescrita coletiva, temos: "Diante dos fatores mensionados, podemos afirmar que, realmente, o povo brasileiro é preconceituoso, pois não aceita conviver com as diferenças, o que é prejudicial para o ser humano.". Na versão reescrita do aluno, lemos: "Então, podemos afirmar que os brasileiros, são preconceituosos, por não aceita conviver com as diferenças, o que acabas prejudicando os brasileiros.". Inclusive o título da versão reescrita do aluno é o mesmo do texto coletivo, com a diferença de estar no plural.

Até mesmo os mecanismos de textualização e enunciativos têm estreita relação com a produção coletiva.

Quanto aos primeiros, há construções frasais e relações de subordinação iguais ou bastante parecidas. Os títulos são idênticos: "O brasileiro é preconceituoso" e "Os brasileiros são preconceituosos". No decorrer do texto do aluno, há orações como "Os brasileiros são preconceituosos, a maioria dos brasileiros tem preconceito até por ele mesmo, os brasileiros tem preconceito pela desigualdade social e as dificuldades de viver com as 
pessoas e as suas diferenças", "Por não aceitar as nossas diferenças, tarmos o Brasil preconceituoso"; na reescrita coletiva, lemos: "O povo brasileiro é discriminado por ele mesmo, pois a sua diversificação é grande, existe a desigualdade social além da intolerância das pessoas para conviver com as diferenças", "Por não aceitarmos as diferenças citadas acima, tornamos o Brasil um país preconceituoso".

Quanto aos segundos, observamos o uso de modalizações idênticas ("podemos afirmar", "não suportam", "se acham"), além do abandono, em relação à primeira versão do texto do aluno, da voz da religião, que revelava uma crença cristã da parte do autor.

Como vemos, o texto é, em grande parte, uma paráfrase da reescrita coletiva em suas capacidades/operações constitutivas, a qual é vista como um modelo a ser copiado. Já o aluno parece não conseguir internalizar os conhecimentos da escrita e utilizá-los em função de sua ação de linguagem, anulando quase inteiramente sua condição de sujeito-autor.

No segundo texto, observamos um fenômeno bastante parecido:

\section{TEXTO 2: PRIMEIRA VERSÃO}

\begin{tabular}{|c|c|}
\hline 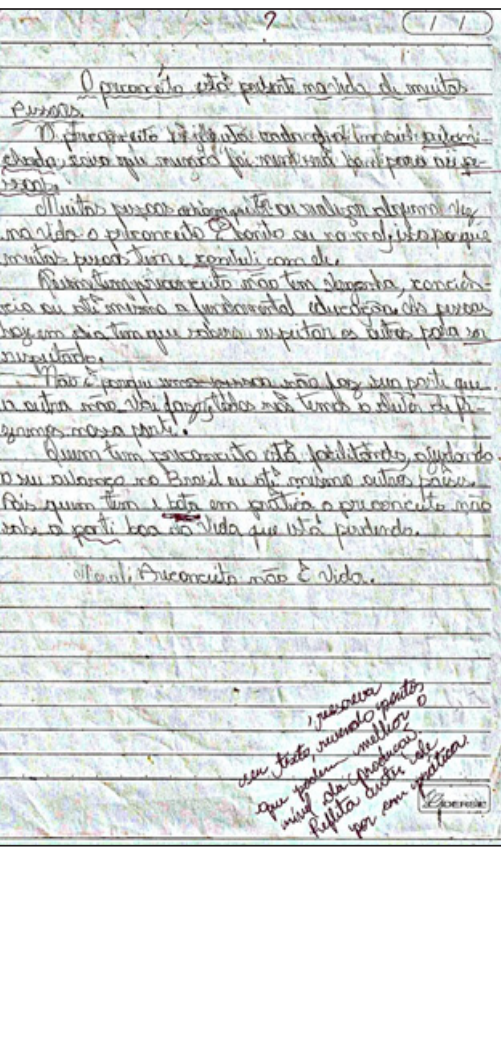 & $\begin{array}{l}\text { O preconceito está cada dia mais } \\
\text { avanchado, coisa que nunca foi nem será } \\
\text { bom para as pessoas. } \\
\text { Muitas pessoas acham que ter ou } \\
\text { realizar alguma vez na vida o preconceito é } \\
\text { bonito ou normal, isso porque muitas pes- } \\
\text { soas tem e convivi com ele. } \\
\text { Quem tem preconceito não tem vergo- } \\
\text { nha, conciência ou até mesmo a fundamental } \\
\text { educação. As pessoas hoje em dia tem que } \\
\text { saber respeitar os outros para ser respeitado. } \\
\text { Não é porque uma pessoa não faz } \\
\text { sua parte que a outra não vai fazer, todos } \\
\text { nós temos o dever de fazermos nossa parte. } \\
\text { Quem tem preconceito está facilitan- } \\
\text { do, ajudando o seu avanço no Brasil ou até } \\
\text { mesmo outros países. Pois quem tem e bota } \\
\text { em prática o preconceito não sabe a parti boa } \\
\text { da vida que está perdendo. } \\
\text { Preconceito não é vida. }\end{array}$ \\
\hline
\end{tabular}




\section{TEXTO 2: VERSÃO REESCRITA}

O preconceito está presente na vida de muitas pessoas

o preconceito está por toda parte do mundo. Existe vários tipos de preconceito ou, pontos que geram o preconceito podemos citar como exemplo; a desigualdade social, a entolerância e também a grande diversificação.

A desigualdade social é um grande problema, pois grande parte das pessoas praticam-a, muitas querem ser mais do que as outras coma aquelas que tem mais condições.

A entolerância outro grande problema e alvo do preconceito, está muito presente na vida das pessoas pois, muitas não suportam seu jeito, não aceitam a se mesmas como; o gordo(a) não suporta ser gordo.

A grande diversificação que tanto se apresenta de várias formas com: cor dos cabelos, da pele, altura, opinião religiosa entre outros. Sendo assim, por não aceitarmos nossas diferenças nos tornamos pessoas preconceituosas.

Diante de vários fatos mensionados, podemos realmente dizer que, o preconceito está presente na vida de muitas pessos por toda parte.

Também nesse caso, a correção do professor na primeira versão restringe-se a aspectos morfossintáticos, e o bilhete no pós-texto tem as mesmas características de observações genéricas verificadas no Texto 1: rever alguns pontos cuja observância pode melhorar o texto. As modificações processadas na versão reescrita em momento algum retomam essas correções ou outros elementos da primeira versão. No caso desse aluno, o controle da reescrita coletiva do professor é ainda mais forte.

o conteúdo temático novamente representa uma paráfrase (quando não uma transcrição) muito fiel do texto coletivo: não há temas nem tratamento deles a não ser aqueles previstos na reescrita coletiva (existe preconceito, em virtude da desigualdade social, da intolerância e da grande diversificação). Ao repetir muitas das ideias (ou quase todas), importa até mesmo o vocabulário mais formal utilizado no texto coletivo.

Também em se tratando da infraestrutura textual, essa fidelidade permanece: $o$ aluno usa uma sequência argumentativa idêntica (um parágrafo de introdução que já prevê os três argumentos, um parágrafo de desenvolvimento para cada um deles e um parágrafo de conclusão com estrutura muito parecida) e os mesmos argumentos (intolerância, desigualdade social e diversificação como fatores que tornam o Brasil um país preconceituoso), alterando somente a ordem de apresentação deles.

No plano linguístico-discursivo, usa estruturas frasais e subordinadas bastante parecidas, principalmente no emprego das orações adverbiais causais - no texto do aluno lemos: "Sendo assim, por não aceitarmos 
nossas diferenças nos tornamos pessoas preconceituosas", "A desigualdade social é um grande problema, pois grande parte das pessoas praticam-a, muitas querem ser mais do que as outras coma aquelas que tem mais condições"; enquanto na reescrita coletiva observamos: "Por não aceitarmos as diferenças citadas acima, tornamos o Brasil um país preconceituoso", "A desigualdade social é outro grande motivo de preconceito, pois as pessoas com mais condições se acham superiores às que têm menos condições". Além disso, emprega conectores idênticos, como "outro", "diante de vários fatos mensionados", o que também ocorre com as modalizações ("podemos afirmar", "realmente", "não suportam", "não aceitam"). Por fim, utiliza com mais frequência, a exemplo do texto coletivo, verbos e pronomes na primeira pessoa do plural, ao passo que anteriormente empregou tais formas em apenas uma frase do texto.

o Texto 2, dessa forma, é quase uma cópia do texto coletivo. O aluno abandona (quase) completamente seu projeto de texto e vê o outro como um modelo definitivo, uma receita a ser seguida fielmente, chegando a transcrever trechos inteiros e a cometer, inclusive, desvios ortográficos do professor ("mensionados").

\section{Discussão dos RESUlTAdos E CONCLUSÃo}

A mediação do outro e do signo é condição essencial à construção de conhecimentos pelos alunos. No caso de atividades de escrita, a interação que se estabelece com o professor é fundamental para isso, e a natureza dela exerce grande influência sobre o resultado da atividade.

Como percebemos nos textos acima, a escrita do professor se introduz com muita intensidade na escrita dos alunos, cujas reescritas passam a ser muito mais paráfrases do texto coletivo reescrito anteriormente do que frutos de um projeto de dizer próprio. Aliás, esse projeto de dizer é (quase) totalmente abandonado: os alunos não tomam a reescrita coletiva como um parâmetro para atuar sobre os seus textos, e sim como um modelo acabado de excelência, o que transforma a tarefa em mera reprodução. Os alunos, dessa forma, não se constituem como autores, pois não vemos nos textos indícios de autoria como aqueles apontados por Possenti (2002): tomada de posição, inserção e avaliação das vozes do outro, ou seja, um projeto de dizer próprio. Pelo contrário, apaga-se a autoria dos textos (tanto na reescrita coletiva quanto na individual): o que ganha destaque é a internalização e uso de certos recursos linguísticos e textuais, como se a produção de textos dispensasse a presença do sujeito como autor. 
Tal atitude pode advir, em parte, do comportamento do professor, na reescrita coletiva, de abandonar o texto do aluno e proceder à escrita de um outro texto independente do primeiro, o que pode ter servido de exemplo para os alunos e motivado neles uma compreensão equivocada do significado da reescrita textual; ou ainda da falta de clareza e da ausência de critérios de algumas correções escritas do professor nos bilhetes do pós-texto (rever alguns pontos do texto, levar em conta o propósito solicitado, organizar as ideias), o que os fez procurar outros parâmetros para atuar em seus próprios textos e encontrá-los na outra forma de mediação: a refacção coletiva. Nesse caso, os alunos passam a escrever mediante o que acreditam ser do gosto do professor: o que este pensa sobre o assunto, o que imagina ser um bom texto, o que gostaria de ler, culminando até na imitação e reprodução de modelos. A consequência é que, em se tratando dessas práticas:

Não se trata de estilização ou apropriação própria da linguagem, mas de uma aplicação de modelos preestabelecidos pelos valores sociais privilegiados. Nesse sentido, o interlocutor acaba não apenas por impor-se ao locutor, mas também por ameaçar destruir o próprio papel de sujeito [ou de autor] que este deveria ter numa relação intersubjetiva (BRITTO, 2003, p. 123).

Conforme observamos, as práticas de reescrita acima analisadas não parecem conduzir à construção de um sujeito-autor que, apropriando-se de diferentes vozes, transforme-as em palavras suas, dotadas de uma expressividade própria (Cf. BAKHTIN, 1997). Tem-se, dessa forma, um empobrecimento dos textos, o que culmina num resultado completamente adverso do que prevemos de práticas de refacção textual. Se pensarmos que o uso social da escrita requer o domínio de um conjunto de habilidades que proporcionem a inserção e a participação dos sujeitos em determinadas atividades no âmbito das quais eles assumem papéis diversos, é indispensável respeitar o projeto de dizer dos alunos e implementar situações de (re) escrita em que tal projeto possa ser exercitado, conjuntamente aos demais conhecimentos necessários ao escritor proficiente. 


\section{REFERÊNCIAS}

ALMEIDA, Marialva do Socorro Ramalho de Oliveira de. Refação como ação pedagógica: o olhar do outro sobre o texto orienta a refacção? 160 f. Dissertação (Mestrado em Linguística Aplicada) - Instituto de Estudos da Linguagem, Universidade Estadual de Campinas, Campinas, 2001. Disponível em: <http://libdigi.unicamp.br/document/?code $=$ vtls000223206 > . Acesso em: $15 / 3 / 2008$.

BAKHTIN, Mikhail. Estética da criação verbal. 2. ed. São Paulo: Martins Fontes, 1997.

BALTAR, Marcos. Competência discursiva e gêneros textuais: uma experiência com o jornal em sala de aula. Caxias do Sul: Educs, 2004.

BAPTISTA, Lívia Márcia Tiba Rádis. Manobras e estratégias de autoria: a singularidade do sujeito na produção escrita em língua espanhola. 2005. 329 f. Tese (Doutorado em Linguística) - Instituto de Estudos da Linguagem, Universidade Estadual de Campinas, Campinas, 2005. Disponível em: <http://libdigi.unicamp.br/document/?code=vtls000362871 >. Acesso em: 19/2/2009.

BRITTO, Luiz Percival Leme. Em terra de surdos-mudos (um estudo sobre as condições de produção de textos escolares). In: GERALDI, João Wanderley (Org.). $O$ texto na sala de aula. 3. ed. São Paulo, Ática, 2003.

BRONCKART, Jean-Paul. Atividade de linguagem, discurso e desenvolvimento humano. Campinas: Mercado de Letras, 2006.

. Atividade de linguagem, textos e discursos: por um interacionismo sócio-discursivo. São Paulo: Educ, 1999.

CABRAL, Manuela. Avaliação e escrita: um processo integrado. In: FONSECA, Fernanda Irene (Org.). Pedagogia da escrita: perspectivas. Porto: Porto Editora, 1994. (Linguística).

D'ELIA, Maria Eugênia Ribeiro. O texto do professor no texto do aluno: intenções e significados. 2007. 104 f. Dissertação (Mestrado em Educação) - Faculdade de Educação, Universidade Estadual de Campinas, Campinas, 2007. Disponível em: <http://libdigi.unicamp.br/ document $/$ code $=$ vtls000416162 $>$. Acesso em: 14/3/2008.

DOLZ, Joaquim; SCHNEUWLY, Bernard. Gêneros e progressão em expressão oral e escrita elementos para reflexões sobre uma experiência suíça (francófona). In: SCHNEUWLY, Bernard; DOLZ, Joaquim. Gêneros orais e escritos na escola. Campinas: Mercado de Letras, 2004. (As faces da linguística aplicada).

GARCEZ, Lucília Helena do Carmo. A escrita e o outro: os modos de participação na construção do texto. Brasília: Editora da UnB, 1998.

GERALDI, João Wanderley. Portos de passagem. 4. ed. São Paulo: Martins fontes, 1997.

POSSENTI, Sírio. Indícios de autoria. Perspectiva, Florianópolis, v. 20, n. 1, p.111-129, jan./jun. 2002. Disponível em: <http://www.perspectiva.ufsc.br/perspectiva_2002_01/20_texto_possenti. pdf > . Acesso em: 19/2/2009.

RUIZ, Eliana. Como se corrige redação na escola. Campinas: Mercado de Letras, 2001. (Ideias sobre linguagem).

SOUZA, Edna Guedes de. Dissertação: gênero ou tipo textual?. In: DIONísıo, Ângela Paiva; BESERRA, Normanda da Silva (Orgs.). Tecendo textos, construindo experiências. Rio de janeiro: Lucerna, 2003.

Submetido em: $14 / 10 / 2011$

Aceito em: 24/07/2012 